Jurnal Keperawatan Padjadjaran

ISSN 2338-5324 (print)

ISSN 2442-7276 (online)

Online di http://jkp.fkep.unpad.ac.id

DOI : $10.24198 / \mathrm{jkp}$

\title{
Psychometric Evaluation of Instruments Measuring The Older Adult's Functional Status in Indonesian
}

\author{
Dara Febriana, Juanita, Nurhasanah \\ Faculty of Nursing Universitas Syiah Kuala, Banda Aceh, Indonesia \\ Corresponding email: dara.febriana@unsyiah.ac.id
}

Submitted: 09-07-2018 Accepted: 24-06-2019 Published: 01-08-2019

\begin{abstract}
For year research on quantifying how well individual's function has been reported. Assessing function is particularly important in the older adults, as the prevalence of functional disability increases with age. In Indonesia, there is a lack of studies that measure the functional status of the older adults. There is even less research on evaluating the psychometric properties of an instrument. Therefore, this study aimed to compare the psychometric properties of the evidence supported functional status instrument consisting of the Short Physical Performance Battery (SPPB), the Functional Status Questionnaire (FSQ) and the Physical Performance Test (PPT). This study using the validation design with descriptive approach. And 401 subjects aged more than 60 years old were recruited purposively from five districts in Aceh. Every instrument showed good validity and reliability and has been used either for research purposes or in clinical setting. All subjects completed the FSQ, SPBB, and FSQ assessment. Correlation between SPPB and PPT were higher than FSQ when assessed for convergent validity the FSQ had comparable correlations with the reported health status. However, relationship between SPPB, PPT and FSQ were inconsistent. The findings of this study is expected to support the psychometric properties of all three instrument for functional status assessment in Indonesian Older adults, and SPPB appear to be the best among the other instruments to use in the nursing practice.
\end{abstract}

Keywords: Assessment, functional status, instrumentation, older adults. 
Dara Febriana: Psychometric Evaluation of Instruments Measuring The Older Adult's Functional Status

\section{Introduction}

Functional status has evolved into one of the patient's outcome criteria and it is an important part in measuring the older adults' health condition. Functional status describes as the patient's perception of how they function on a daily basis (Wang, 2003). Maintaining and enhancing the individual's ability to gain functional independence in self-care, mobilization and social activities has been widely identified as the goal of nursing service delivery. Even some nursing theorists such as Dorothea Orem and Sister Calista Roy incorporate functional status into the theoretical frameworks of their theory. In addition, functional status also has been included into the outcome criteria of nursing intervention (Doran, 2011).

The older adults often come to health care services with acute or chronic health problems that affect their functional ability. Decline in functional ability is often followed by a decrease in independence. However, this process is not unchangeable, it can be prevented by recognizing the signs of functional degradation so that appropriate interventions can be determined to prevent functional decline (Quinn, McArthur, Ellis, \& Stott, 2011).

Over the past two decades, there has been considerable progress in the assessment of functional status and disability in the older population. Older adult who lives in the community, screening and assessment are key factors for detecting early onset of functional and disability deficits. Functional assessment provides guidance for determining gerontology nursing interventions, and also provides baseline data for evaluation of the effectiveness of interventions. Functional status is beneficial to study because it can be used as a significant clinical predictor, and also indirectly can be utilized as disability predictors, placement in institution and even death (Gill, 2010). Therefore, classification and functional assessment of the older adults greatly affect nursing practice, health care systems, as well as for researchers and policy makers (Cieza \& Stucki, 2008). However, the choice of appropriate instruments depends on the measured constructs, the ecological aspects of the instrument and their validity and reliability (Freiberger et al., 2012).

Functional status often assessed by physical performance tests, in which an individual is required to perform a specific task (or set of tasks) and objectively evaluated, by default using predetermined criteria, which may include counting repetitions or corresponding activity times (Gill, 2010). There are several instruments to measure functional status currently available, but most of these instruments are used in patients undergoing rehabilitation programs or with certain disease conditions such as patients with dementia and mentally impaired patients, therefore not all instruments are suitable for assessing functional status in general older adults.

After extensive literature review, the researchers found three commonly used instruments for measuring functional status and could be used in the older adult's population they are: (1) Short Physical Performance Battery (SPPB) (Guralnik et al., 1994), (2) Functional Status Questionnaire (FSQ) (Cleary \& Jette, 2000; Jette et al., 1986), and (3) The Physical Performance Test (PPT) (Reuben \& Siu, 1990; Sherman \& Reuben, 1998). The criteria used to determine the instrument to be used for this study include (1) has passed the validity and reliability test, (2) easy to use (no special training required), (3) free of charge, (4) required short time for the assessment for a maximum of 10 minutes and (5) can be used for the older adults who are less educated.

According to Caprio and Williams (2007), the most commonly used instrument to assess functional status is Katz Index and Barthel Index. Katz Index usually used to examine the functional status of a person in performing their daily activities and Barthel Index was used to examines the functional capabilities of individuals day to day activity and mobility (Mahoney \& Barthel, 1965; VanSwearingen \& Brach, 2001; Zeltzer, 2008). However, both instruments only focus on a person's ability to perform daily activities, while functional status not only examines ADL but also physical, emotional and social skills. In Indonesia the instrument used to assess functional status is still very limited. The SPBB, FSQ, and PPT are not too often used in Indonesia although 
the psychometric properties of these three instruments have been recognized globally (Cleary \& Jette, 2000; Freiberger et al., 2012; Gill, 2010). In addition, systematic reviews from the literature review have confirmed the validity and reliability of SPBB, FSQ and PPT, even recommending the three instruments to be used in clinical practice (Freiberger et al., 2012; Moore, Palmer, Patterson, \& Jeste, 2007). However, no prior studies have compared the psychometric properties of the three instruments was found. Based on the above explanation and taking into account the limited research in the older adult's population with regard to their functional status measurement, the researcher is interested in conducting research to determine which of these three instruments is most suitable for use in the context of older adult's population in Indonesia. Moreover, this study also compared the validity and reliability of SPPB, FSQ and PPT.

\section{Method}

Research subjects were recruited through direct contact, after getting permission with the village head. This study recruited subjects by purposive sampling that is the selection method based on certain requirements, they are: (1) aged 60 years and above (2) did not suffer severe cognitive impairment as evidenced by the Short Portable Mental Status Questionnaire (SPMSQ) with score less than 8 (severe cognitive impairment). For validation research such as this research, random sampling technique is not very necessary because the sample in this research were considered to be homogeneous. The study recruited 401 samples of older adults living in the community, most sample assessed at their homes, some of them were evaluated at the primary health care center and some were at village activity center. Data collection is conducted by 5 enumerators who have been trained prior to data collection.

After the verbal informed consent, respondent was asked to fill out the demographic data questionnaire and Functional Status Questionnaire (FSQ) through a guided interview, followed by an assessment using the Short Physical
Performance Battery (SPPB) and Physical Performance Test (PPT) form. A summary of the overall research instruments is provided in Table 1.

FSQ is a multi-item instrument and is a self-administered instrument type. In this study we used all components of the FSQ consisting of (1) Basic Activities of Daily Living (FSQ BADL), (2) Intermediate Activities of Daily Living (FSQ IADL), (3) Psychological Function (FSQ FP), (4)) Social function/role (FSQ FS), social activities (FSQ FSKS), and quality of social interaction (FSQ FSKIS) and (5) single item consisting of 6 questions (IT). The FSQ asks respondents to indicate their function from 4 weeks before. Response options for the FSQ show the degree of difficulty felt related to the tasks in the FSQ item statement, and the choice of answers given between: usually can be without difficulty, little difficulty, many difficulties, usually not done for health reasons, and usually not done because other reasons. Scores for each sub-scale range from 0 , indicating the worst function, to 100 , indicating the best function. The warning zone is under 90 and 73 for BADL and IADL sub-scales. If patient or respondent scores are in the warning zone then according to the assessment of various interdisciplinary groups they have impaired function and should receive clinical attention (Jette et al., 1986).

SPPB and PPT are instruments used to evaluate the ability of respondents to perform a series of tasks. SPPB consists of three assessment hierarchies that start from the balance test, walk speed test and standing test from the chair five times. Each assignment is scored from 0 (poor performing task) to 4 (execution of good task) (Guralnik et al., 1994). PPT can ideally be completed within 5 minutes and requires only one checker and several tools that are easy to find. Seven physical functions are assessed, among others: (1) write the phrase "whale living in the blue sea", (2) simulation of eating, (3) lift the book and put it on a shelf that is higher than the respondent's arm length, (4) wear and remove jacket, (5) take a coin from the floor, (6) rotate 360 degrees, (7) walk 50 feet, (8) using stairs for one try, and (9) using stairs for several times. Each item is scaled 5 
Dara Febriana: Psychometric Evaluation of Instruments Measuring The Older Adult's Functional Status

points ( $0-4), 0$ indicates "inability to perform task" and 4 indicates the fastest or best time to perform the task. A high score means the respondent has a good function, the best score is 36 (D. B. Reuben \& Siu, 1990). For this study we used a total of 9 items, for respondents who did not have stairs in their home, data collection was performed in village activities centre.

Before the instrument administered, all of the tool have been through the process of back translation, which is a process of translating an instrument using a bilingual expert (Brislin, 1970). The instrument in this study was originally in English, therefore the first step was to translated it into Indonesian by a bilingual translator, then translated back to English by a different bilingual translator. The second English version is compared to the original version to see if there is any difference in meaning. Due to the absence of meaningful meaning differences, the translated instrument in Indonesian can be used for this research.

Data analysis for this study consist of descriptive and inferential statistic. Descriptive statistics were used for analysing socio-demographic characteristics in form of frequencies, percentages, means, and standard deviation. For inferential statistics pearson product moment correlation coefficient was used to analyse convergent validity of the three scales. Spearman rank correlation was also used to analyse the test-retest reliability.

Table 1 Functional Status Measurement Tools

\begin{tabular}{|c|c|c|c|}
\hline Scale/Items & $\begin{array}{c}\text { Data Collection } \\
\text { Procedure }\end{array}$ & Respond Format & Scoring Method (range) \\
\hline FSQ BADL/3 & Interview/self-report & Level of difficulty & $\begin{array}{l}\text { Standardization } \\
(0-100)\end{array}$ \\
\hline FSQ IADL/7 & Interview/self-report & Level of difficulty & $\begin{array}{l}\text { Standardization } \\
\quad(0-100)\end{array}$ \\
\hline FSQ FP/5 & Interview/self-report & Frequency & $\begin{array}{l}\text { Standardization } \\
(0-100)\end{array}$ \\
\hline FSQ FS/6 & Interview/self-report & Frequency & $\begin{array}{l}\text { Standardization } \\
\quad(0-100)\end{array}$ \\
\hline FSQ FSKS/3 & Interview/self-report & Level of difficulty & $\begin{array}{l}\text { Standardization } \\
\quad(0-100)\end{array}$ \\
\hline FSQ FSKIS/5 & Interview/self-report & Frequency & \\
\hline FSQ IT/6 & Interview/self-report & & \\
\hline Work situation & & Work option & $1-6$ \\
\hline Days in bed & & Days count & $0-30$ days \\
\hline Restricted days & & Days count & 0-30 days \\
\hline $\begin{array}{l}\text { 4. Sexual } \\
\text { Relationship }\end{array}$ & & $\begin{array}{l}\text { 4. Level of } \\
\text { satisfaction }\end{array}$ & $1-6$ \\
\hline $\begin{array}{ll}\text { 5. } & \text { Perception about } \\
\text { health } & \end{array}$ & & $\begin{array}{l}\text { 5. Level of } \\
\text { satisfaction }\end{array}$ & $1-6$ \\
\hline $\begin{array}{l}\text { 6. Gathering with } \\
\text { family and friends }\end{array}$ & & $\begin{array}{l}\text { 6. Gathering } \\
\text { frequency }\end{array}$ & $1-6$ \\
\hline SPPB Balance test $/ 3$ & Observation & Timing & Standardization \\
\hline SPPB Speed test $/ 1$ & Observation & Timing & Standardization \\
\hline SPPB Chair stand/2 & Observation & Timing & Standardization \\
\hline PPT/9 & Observation & Timing & $0-4 /$ item \\
\hline
\end{tabular}


Dara Febriana: Psychometric Evaluation of Instruments Measuring The Older Adult's Functional Status

\section{Results}

Table 2 shows the overall characteristics of the respondents involved in the study. The average age of respondents is 66.30 years (SD 5.71). The sample is generally in the 60-70-year age group (older adults group), dominated by female respondents, married, and domiciled in Aceh Pidie and Aceh Utara. Almost all respondents have chronic disease, which is dominated by cardiovascular disease, arthritis and diabetes mellitus. The duration of the disease is predominantly 1-5 years range and the main caregiver is their child and spouse respectively. The education of respondents is almost half as low and they do not have job to support their economy. Cognitive function mostly in low category and majority of the respondents reported that their health status was quite healthy.

Table 2 Respondent characteristics

\begin{tabular}{|c|c|}
\hline Socio-demographic Characteristics & Total $(n=401)$ \\
\hline \multicolumn{2}{|l|}{ Age (years) } \\
\hline $60-74$ & $368(91.8 \%)$ \\
\hline $75-89$ & $31(7.7 \%)$ \\
\hline$>90$ & $2(0.5 \%)$ \\
\hline \multicolumn{2}{|l|}{ Gender } \\
\hline Female & $231(57.6 \%)$ \\
\hline Male & $170(42.4 \%)$ \\
\hline \multicolumn{2}{|l|}{ Status } \\
\hline Married & $220(54.9 \%)$ \\
\hline Widow/widower & $126(31.4 \%)$ \\
\hline Single & $46(11.5 \%)$ \\
\hline Separated & $9(2.2 \%)$ \\
\hline \multicolumn{2}{|l|}{ Location } \\
\hline Pidie & $96(23.9 \%)$ \\
\hline Aceh Utara & $96(23.9 \%)$ \\
\hline Bireun & $94(23.4 \%)$ \\
\hline Aceh Besar & $68(17 \%)$ \\
\hline Aceh Timur & $47(11.7 \%)$ \\
\hline \multicolumn{2}{|l|}{ Having chronic illness } \\
\hline Yes & $377(94 \%)$ \\
\hline No & $24(6 \%)$ \\
\hline \multicolumn{2}{|l|}{ Name of disease $(n=377)$} \\
\hline Cardiovascular diseases & $162(43 \%)$ \\
\hline Arthritis & $138(36.7 \%)$ \\
\hline Diabetes mellitus & $42(11.1 \%)$ \\
\hline Gastrointestinal disease & $23(6 \%)$ \\
\hline Lung and respiration disease & $8(2 \%)$ \\
\hline Others & $4(1 \%)$ \\
\hline \multicolumn{2}{|l|}{ Morbidity $(\mathrm{n}=377$ ) } \\
\hline Single & $262(69.5 \%)$ \\
\hline Multiple & $115(30.5 \%)$ \\
\hline Illness duration (years) $(n=377)$ & \\
\hline
\end{tabular}


Dara Febriana: Psychometric Evaluation of Instruments Measuring The Older Adult's Functional Status

\begin{tabular}{|c|c|}
\hline $1-5$ & $204(54.1 \%)$ \\
\hline $6-10$ & $150(39.8 \%)$ \\
\hline $11-15$ & $18(4.8 \%)$ \\
\hline $16-20$ & $5(1.3 \%)$ \\
\hline \multicolumn{2}{|l|}{ Primary Caregiver } \\
\hline Children & $196(48.9 \%)$ \\
\hline Spouse & $184(45.9 \%)$ \\
\hline Next of kin & $19(4.7 \%)$ \\
\hline Paid caregiver & $2(0.5 \%)$ \\
\hline \multicolumn{2}{|l|}{ Education } \\
\hline Elementary school & $180(44.9 \%)$ \\
\hline No formal education & $149(37.2 \%)$ \\
\hline Junior/senior high school & $50(12.5 \%)$ \\
\hline Diploma & $20(5 \%)$ \\
\hline Bachelor & $2(0.5 \%)$ \\
\hline \multicolumn{2}{|l|}{ Occupation } \\
\hline Do not work & $258(64.3 \%)$ \\
\hline Farmer & $90(22.4 \%)$ \\
\hline Merchant & $27(6.7 \%)$ \\
\hline Retired & $21(5.2 \%)$ \\
\hline Others & $5(1.1 \%)$ \\
\hline \multicolumn{2}{|l|}{ SPSMQ } \\
\hline Low & $175(43.6 \%)$ \\
\hline Intact & $164(40.9 \%)$ \\
\hline Moderate & $62(15.5 \%)$ \\
\hline \multicolumn{2}{|l|}{ Health Status } \\
\hline Quite healthy & $244(60.8 \%)$ \\
\hline Good & $123(30.7 \%)$ \\
\hline Very healthy & $25(6.2 \%)$ \\
\hline Not healthy & $9(2.2 \%)$ \\
\hline
\end{tabular}

Table 3 Central tendency, range and internal consistency for measuring functional status (FSQ, SPPB, and PPT)

\begin{tabular}{lcccccc}
\hline \multicolumn{1}{c}{ Scale } & Mean & $\begin{array}{c}\text { Standard } \\
\text { Deviation }\end{array}$ & $\begin{array}{c}\text { Observed } \\
\text { Range }\end{array}$ & $\begin{array}{c}\text { \% } \\
\text { floor }\end{array}$ & $\begin{array}{c}\text { \% } \\
\text { ceiling }\end{array}$ & $\begin{array}{c}\text { Internal } \\
\text { Consistency, } \\
\text { Cronbach's } \\
\boldsymbol{\alpha}\end{array}$ \\
\hline FSQ BADL & 85.56 & 18.35 & $33.33-100$ & 3 & 52 & 0.88 \\
FSQ IADL & 43.10 & 19.47 & $0-94.44$ & 1 & 0 & 0.82 \\
FSQ FP & 74.17 & 13.60 & $28-100$ & 0 & 6 & 0.72 \\
FSQ FS & 49.97 & 14.66 & $0-94.44$ & 2 & 1 & 0.53 \\
FSQ FSKS & 64.92 & 25.40 & $0-100$ & 0 & 9 & 0.89 \\
FSQ FSKIS & 80.63 & 11.20 & $40-100$ & 0.43 \\
\hline
\end{tabular}


Dara Febriana: Psychometric Evaluation of Instruments Measuring The Older Adult's Functional Status

\begin{tabular}{lcccccc}
\hline SPPB & 6.93 & 2.62 & $0-12$ & 1 & 1 & 0.80 \\
PPT & 20.43 & 7.27 & $2-34$ & 1 & 0 & 0.91 \\
\hline
\end{tabular}

Table 4 Correlation between scales measuring functional status

\begin{tabular}{|c|c|c|c|c|c|c|c|c|}
\hline $\begin{array}{c}\text { Instruments } \\
\text { Name }\end{array}$ & $\begin{array}{c}\text { FSQ } \\
\text { BADL }\end{array}$ & $\begin{array}{l}\text { FSQ } \\
\text { IADL }\end{array}$ & FSQ FP & FSQ FS & $\begin{array}{l}\text { FSQ } \\
\text { FSKS }\end{array}$ & $\begin{array}{c}\text { FSQ } \\
\text { FSKIS }\end{array}$ & SPPB & PPT \\
\hline FSQ BADL & 1 & & & & & & & \\
\hline FSQ IADL & $0.62^{* *}$ & 1 & & & & & & \\
\hline FSQ FP & $0.36^{* *}$ & $0.38^{* *}$ & 1 & & & & & \\
\hline FSQ FS & $0.46^{* *}$ & $0.56^{* *}$ & $0.45^{* *}$ & 1 & & & & \\
\hline FSQ FSKS & $0.67^{* *}$ & $0.78^{* *}$ & $0.42^{* *}$ & $0.60^{* *}$ & 1 & & & \\
\hline FSQ FSKIS & $0.43^{* *}$ & $0.40^{* *}$ & $0.38^{* *}$ & $0.19^{* *}$ & $0.42^{* *}$ & 1 & & \\
\hline SPPB & $0.61^{* *}$ & $0.72^{* *}$ & $0.30^{* *}$ & $0.49^{* *}$ & $0.66^{* *}$ & $0.20^{* *}$ & 1 & \\
\hline PPT & $0.74^{* *}$ & $0.79^{* *}$ & $0.41^{* *}$ & $0.53^{* *}$ & $0.79^{* *}$ & $0.49^{* *}$ & $0.79^{* *}$ & 1 \\
\hline
\end{tabular}

All instruments have been confirmed and filled before the enumerators leave the study site. The mean and standard deviation of all instruments measuring functional status can be seen in table 3. There are no significant floor and ceiling effects for FSQ IADL, FSQ FS, SPBB and PPT. As for FSQ BADL, FSQ FSKS and FSQ FSKIS the effects of floor and ceiling are significant. Nunnally in the later version of his Pychometric theory book (1994) suggested a geater than 0.7 was considered to have acceptable internal consistency (Streiner, 2003). Therefore, the internal consistency of these three instruments considerd to be adequate for every subscale, especially PPT, but for FSQ FS and FSQ FSKIS internal consistency is lower than other subscale.

Correlation between scales can be seen in table 4 . The highest correlation is at the value of $\mathrm{r}=0.79$ is in the correlation between PPT with FSQ IADL, PPT with FSQ with FSKS and PPT with SPPB. The low correlation is at the value of $r=0.19$ that is the correlation between FSQ FSKIS with FSQ FS. The correlation between SPPB and PPT is the highest and both instruments are equally measuring the functional status of the older adults by means of observation.

\section{Discussion}

The main research objective of this research is to determine which of these three instruments (FSQ, SPPB, and PPT) can be used to measure functional status of older adults population in Indonesia which one is most appropriate. To determine the suitability of course one of the basic thing to do is to determine the reliability and validity of the instruments. We found in studies conducted on older adults people living in the community that almost all instruments have the potential to be used as a standard instrument to measure functional status of older adults living in the community, especially SPPB and PPT. both are internally consistent with Cronbach's $\alpha$ 0.80 and 0.91 and both also do not experience floor and ceiling effects and have good construct validity.

The second research objective was to compare the validity and reliability of the three instruments; this was obtained by looking at the correlation between the instruments. Two observation instruments have a high correlation with each other $(r$ $=0.79$ ) both are well correlated to the selfreported instrument that can either be filled by the respondent themself or through a guided interview. PPT particularly has a fairly high correlation value with FSQ $(r=0.41-0$. 
79) compared to SPBB with FSQ ( $r=0.20$ - 0.72). These results indicate that SPPB and PPT are potentially useful as screening tool at the primary care level.

FSQ consists of several subscales within it scale, in contrast to other instruments in this study FSQ does not use sum scores for all items in its instrument, but uses sum for each subscale. Therefore, it can be concluded why for some subscales the correlation was very low especially subscales other than FSQ BADL and FSQ IADL. Several studies only use these two subscales in evaluating functional status (Reuben, Valle, Hays, \& Siu, 1995; Sherman \& Reuben, 1998). But for this study researchers decided to include the entire subscale and items. This was done so that all components in the instrument can be seen whether it is suitable for Indonesian older adults. After going through the process of translation, data collection and analysis, FSQ proved to have many weaknesses. In the translation process there were no grammatical errors nor significant differences from the original. However, enumorators reported that they had difficulty when asking one question related to the older adult sexual activities. Therefore, this particular questions "during the past month, how satisfied are you with your sexual relationship? Was changed to "during the past month, are you still sleeping in the same room with your husband?". Surely this option is was not the best one, but to increase response rate and interest of respondents this is the most possible solution. Further research maybe needed to assess FSQ cultural context. Cronbach's $\alpha$ for the overall subscale in FSQ is quite good, especially FSQ BADL (0.88) and FSQ IADL (0.82), but Cronbach's $\alpha$ for FSQ FS and FSQ FSKIS are very low 0.53 and 0.43 . The highest inter-subscale correlation in FSQ is between FSQ IADL and FSQ FSKS $(r=0.78)$ and the lowest correlation is between FSQ FS and FSQ FSKIS $(r=0.19)$. Although the reliability and correlation of FSQ is lower than SPPB and PTT but there are some advantages of FSQ among others objective instruments, it was the existence of subscales which inquire about psychological and social aspects affecting functional status of older adults.
SPPB and PPT in term of their validity and reliability are in better quality than FSQ especially PPT with the highest value of Cronbach's $\alpha$ at 0.91 . Both the translation and data analysis of this instrument do not experience significant problems. But the problem is during data collection mainly for PPT. One of the tasks in PPT relates to the ability of the older adults to write, it is certainly difficult to do if the older adults are illiterate. Then evaluation related to the use of stairs. Not all houses have stairs so it will be difficult to assess the older adult's ability to climb up and down stairs. The solution to this problem was to use the 7 items of questions rather than 9. For this study researchers wanted all items to be evaluated. Therefore, for the older adults who do not have stairs data collection was conducted at the village activity centre. SPPB on the other hand has almost no significant constraints from the process of translation to the data analysis. Based on the preferences asked to the older adults they also prefer SPPB compared to other instruments. Enumerators also report the same thing that SPPB is the easiest to use.

To answer the research question about which instrument is most suitable for the Indonesian context, we are recommending SPPB based on our data. SPPB does not require any modification at all and also easy to administer.

\section{Conclusion}

The findings of this study is expected to support the validity and reliabilty of all three instrument for functional status assessment in Indonesian older adults, and SPPB appear to be the best among the other instruments to use in the nursing practice followed by PPT and FSQ.

\section{References}

Brislin, R. W. (1970). Back-Translation for Cross-Cultural Research. Journal of CrossCultural Psychology, 1(3), 185-216. https:// doi.org/10.1177/135910457000100301. 
Dara Febriana: Psychometric Evaluation of Instruments Measuring The Older Adult's Functional Status

Caprio, T. V., \& Williams, T. F. (2007). Comprehensive geriatric assessment. In E. H. Duthie, P. R. Katz \& M. L. Malone (Eds.), Practice of Geriatrics (4th ed.). Philladelphia: Elsevier Saunders.

Cleary, P. D., \& Jette, A. M. (2000). Reliability and validity of the Functional Status Questionnaire. Quality of Life Research, 9, 747-753.

Cieza, A, \& Stucki, G. (2008). The international classification of functioning disability and health: Its development process and content validity. European Journal of Physical and Rehabilitation Medicine, 44(3), 303-313.

Doran, D. (2011). Nursing Outcomes the State of the Science. Sudbury, MA: Jones \& Bartlett Learning.

Freiberger, E., de Vreede, P., Schoene, D., Rydwik, E., Mueller, V., Frändin, K., \& HopmanRock, M. (2012). Performancebased physical function in older communitydwelling persons: a systematic review of instruments. Age and Ageing. doi: 10.1093/ ageing/afs099.

Gill, T. M. (2010). Assessment of Function and Disability in Longitudinal Studies. Journal of the American Geriatrics Society, 58, S308-S312. doi: 10.1111/j.15325415.2010.02914.X

Guralnik, J. M., Simonsick, E. M., Ferrucci, L., Glynn, R. J., Berkman, L. F., Blazer, D. G., ... Wallace, R. B. (1994). A short physical performance battery assessing lower extremity function: association with selfreported disability and prediction of mortality and nursing home admission. Journal of Gerontology, 49(2), M85-94.

Jette, A. M., Davies, A. R., Cleary, P. D., Calkins, D. R., Rubenstein, L. V., Fink, A., ... Delbanco, T. L. (1986). The Functional Status Questionnaire. Reliabilty and validity when used in primary care. J Gen Intern Med, $1,143-149$.

Mahoney, F. I., \& Barthel, D. W. (1965).
Functional evaluation: the Barthel Index. Maryland State Medical Journal, 14, 56-61.

Moore, D.J., Palmer, B.W., Patterson, T.L., \& Jeste, DV. (2007) A review of performancebased measures of functional living skills. Journal of Psychiatric Research, 41(1-2), 97-118.

Quinn, T. J., McArthur, K., Ellis, G., \& Stott, D. J. (2011). Functional assessment in older people. BMJ, 343. doi: 10.1136/bmj.d4681.

Reuben, D. B., \& Siu, A. L. (1990). An objective measure of physical function of elderly outpatients. The Physical Performance Test. Journal of the American Geriatrics Society, 38(10), 1105-1112.

Reuben, D. B., Valle, L. A., Hays, R. D., \& Siu, A. L. (1995). Measuring physical function in community-dwelling older persons: a comparison of self-administered, Interviewer-administered, and performancebased measures. Journal of American Geriatrics Society, 43(1).

Sherman, S. E., \& Reuben, D. (1998). Measures of Functional Status in CommunityDwelling Elders. Journal of General Internal Medicine, 13(12), 817-823. https://doi. org/10.1046/j.1525-1497.1998.00245.x.

Streiner, D. L. (2003). Starting at the beginning: an introduction to coefficient alpha and internal consistency. Journal of Personality Assessment, 80, 99-103 .

VanSwearingen, J.M., \& Brach, J.S. (2001). Making geriatric assessment work: Selecting useful measures. Physical Therapy, 81(6), 1233-5.

Wang, T.J. (2004). Concept analysis of functional status. International Journal of Nursing Studies, 41, 457-462.

Zeltzer, L. (2008). Psychometric Evaluation of Functional Independence Measure (FIM). Retrieved 8 January 2017, from http://www. medicine.mcgill.ca/strokengine-assess/ module_fim_psycho-en.html. 